\title{
Update on the genetics of congenital myopathies
}

\author{
Pelin, Katarina
}

2019-04

Pelin , K \& Wallgren-Pettersson, C 2019 , ' Update on the genetics of congenital myopathies

' , Seminars in pediatric neurology. , vol. 29 , pp. 12-22 . https://doi.org/10.1016/j.spen.2019.01.005

http://hdl.handle.net/10138/317086

https://doi.org/10.1016/j.spen.2019.01.005

publishedVersion

Downloaded from Helda, University of Helsinki institutional repository.

This is an electronic reprint of the original article.

This reprint may differ from the original in pagination and typographic detail.

Please cite the original version. 


\title{
Update on the Genetics of Congenital Myopathies
}

\author{
Katarina Pelin, $\mathrm{PhD},{ }^{*,+}$ and Carina Wallgren-Pettersson, $\mathrm{MD}, \mathrm{PhD}^{\dagger}$
}

\begin{abstract}
The congenital myopathies form a large clinically and genetically heterogeneous group of disorders. Currently mutations in at least 27 different genes have been reported to cause a congenital myopathy, but the number is expected to increase due to the accelerated use of next-generation sequencing methods. There is substantial overlap between the causative genes and the clinical and histopathologic features of the congenital myopathies. The mode of inheritance can be autosomal recessive, autosomal dominant or X-linked. Both dominant and recessive mutations in the same gene can cause a similar disease phenotype, and the same clinical phenotype can also be caused by mutations in different genes. Clear genotype-phenotype correlations are few and far between.
\end{abstract}

Semin Pediatr Neurol 29:12-22 @ 2019 Elsevier Inc. All rights reserved.

\section{Introduction}

The application of next-generation sequencing methods, I such as whole-exome sequencing, targeted gene panels, and whole-genome sequencing has resulted in an accelerated discovery of novel disease genes and disease-causing variants underlying the various types of congenital myopathies. Furthermore, the use of custom high-density oligonucleotide arrays for comparative genomic hybridization has enabled the discovery of large copy number variations (CNVs) causing, for example, nemaline myopathy and centronuclear myopathy.

The inheritance of congenital myopathies can be autosomal dominant, autosomal recessive or X-linked. De novo dominant disease-causing variants are common in some genes, for example, ACTA1 and TPM2. ${ }^{4,5}$ Both dominant and recessive variants have been described in several genes, for example, ACTA1, TPM2, TPM3, RYR1, MYH2, and TTN. ${ }^{4-8}$ Interestingly, epigenetic silencing of a wild-type allele can result in

From the * Molecular and Integrative Biosciences Research Programme, Faculty of Biological and Environmental Sciences, University of Helsinki, Helsinki, Finland.

${ }^{\dagger}$ The Folkhälsan Institute of Genetics, Folkhälsan Research Center, and Department of Medical and Clinical Genetics, University of Helsinki, Helsinki, Finland.

Supported in part by the Sigrid Jusélius Foundation, the Association Française contre les Myopathies grant no. 18761, the Finska Läkaresällskapet, Muscular Dystrophy UK grant no. 16NEM-PG360094, and the Medicinska understödsföreningen Liv och Hälsa.

Address reprint requests to Katarina Pelin, PhD, Faculty of Biological and Environmental Sciences, University of Helsinki, P.O.Box 56 (Viikinkaari 9), FI-00014 Helsinki, Finland. E-mail: Katarina.Pelin@helsinki.fi monoallelic expression of a mutant allele causing a congenital myopathy. This has been described for RYR1 and core myopathies. ${ }^{9}$ Furthermore, it has been suggested that a common pathophysiological pathway caused by epigenetic changes is activated in some forms of congenital myopathies. ${ }^{10}$

Mutations in the same gene can result in more than 1 clinical phenotype, and the same clinical phenotype can result from mutations in several different genes. ${ }^{11}$ There is also substantial variation in the severity of the clinical phenotype, even within 1 genetic entity, seldom with any discernible genotype-phenotype correlations. ${ }^{12}$

\section{Nemaline Myopathies Including Cap Myopathy and Fiber-Type Disproportion}

The clinical spectrum of nemaline myopathies (NM) is wide, ranging from severe congenital forms, sometimes already detectable in utero, through the typical form to milder childhoodonset and even adult-onset forms. Nemaline rods, derived from sarcomeric $Z$ discs, and often type 1 fiber predominance, are characteristic pathological features of NM. Cap myopathy is pathologically characterised by cap-like structures of disorganised myofibrils and thickened $\mathrm{Z}$ discs, but usually no large rods. ${ }^{11}$ Following the description of families and patients with variable presence of nemaline rods and/or caps, ${ }^{13,14} \mathrm{NM}$ and cap myopathy are considered to be overlapping entities. Fibertype disproportion (FTD), that is, type 1 hypotrophy in the 
presence of larger type 2 fibers, but in the absence of specific pathological features, may be caused by the same genes as NM and cap myopathy. ${ }^{11}$ FTD and type 1 fiber predominance are common features in the other congenital myopathies also, caused by mutations in other genes.

Eleven NM-causing genes have been described to date ${ }^{15-25}$ (Fig., Table). Seven of these genes, that is, ACTA1, NEB, TPM2, TPM3, TNNT1, LMOD3, and MYPN, encode structural proteins of the skeletal muscle sarcomere, CFL2 regulates actin filament dynamics and is essential for muscle maintenance, whereas three of the genes, that is, KBTBD13, KLHL40, and KLHL41, encode proteins involved in the maintenance of sarcomeric integrity by regulating turnover of sarcomeric proteins.

\section{The Nebulin Gene (NEB)}

Disease-causing variants in the nebulin gene (NEB) are the most common cause of autosomal recessive NM, accounting for approximately 50\% of all NM cases, and the most common cause of the typical form. The majority of the patients are compound heterozygous for 2 different NEB mutations. Point mutations causing aberrant splicing, small indels causing frameshifts, and nonsense mutations are the most common mutation types in NEB. ${ }^{12}$ A custom high-density oligonucleotide array, the NM-CGH array, has revealed several large, 1-143 kb, CNVs in NEB, including recurrent $\mathrm{CNVs}$ in the triplicate region spanning exons 82-105.,26 Eight exons are repeated 3 times in the 32 -kb triplicate (TRI) region of NEB, and the normal copy number is 6 (3 copies in each allele). Deletion or duplication of one TRI copy is nonpathogenic, but gains of 2 or more TRI copies segregate with $\mathrm{NM}$ in $4 \%$ of the families studied, and are, thus, interpreted to be pathogenic. The CNVs in the TRI region of NEB can currently be detected only using the NM-CGH-array. ${ }^{26}$ We have estimated that a large pathogenic CNV in NEB is present in $10 \%-15 \%$ of NM patients.
Missense variants are very common in NEB. In the current release of the ExAC Browser (http://exac.broadinstitute.org), $63 \%$ of the variants in the coding region (including splice sites and UTRs) of NEB are missense, 24\% are synonymous changes, and $4 \%$ are apparent pathogenic variants (nonsense, splice site, frameshift, indels). Most of the missense variants are rare, $76 \%$ of the variants being present in only 1-3 heterozygous carriers (allele frequencies well below 0.01). This makes the interpretation of the pathogenicity of missense variants extremely difficult. Our current recommendation is that only variants affecting conserved actin- and tropomyosin-binding sites in NEB can readily be considered as pathogenic, but all the others require functional studies for assessment of their pathogenicity. Actin- and tropomyosin-binding experiments may be used for this purpose. ${ }^{27}$

In addition to the "classical" forms of NM, recessive diseasecausing variants in NEB may cause distal nebulin myopathy without nemaline rods, ${ }^{28}$ core-rod myopathy ${ }^{29}$ distal forms of $\mathrm{NM}^{30}$ and lethal multiple pterygium syndrome. ${ }^{31}$

To date, only 1 clearly dominant NEB variant has been found. It is a $\sim 100 \mathrm{~kb}$ in-frame deletion spanning NEB exons 14-89 resulting in the expression of substantially smaller nebulin proteins, expected to have a dominant-negative effect. This variant segregates with a distal form of NM in a 3-generation Finnish family.

\section{The Skeletal Muscle Alpha-Actin Gene (ACTA1)}

According to our estimate, $23 \%$ of NM cases are caused by mutations in ACTA1. Most of the pathogenic variants in ACTA1 are dominant (90\%) missense variants, most often causing severe NM. Of the sporadic cases with ACTA1 variants, approximately $85 \%$ have been shown to be caused by de novo missense variants. Autosomal recessive variants are rarer (10\%), and result in null alleles (splice site, nonsense, frameshift, and some missense variants). ${ }^{32}$ Dominant variants inherited across

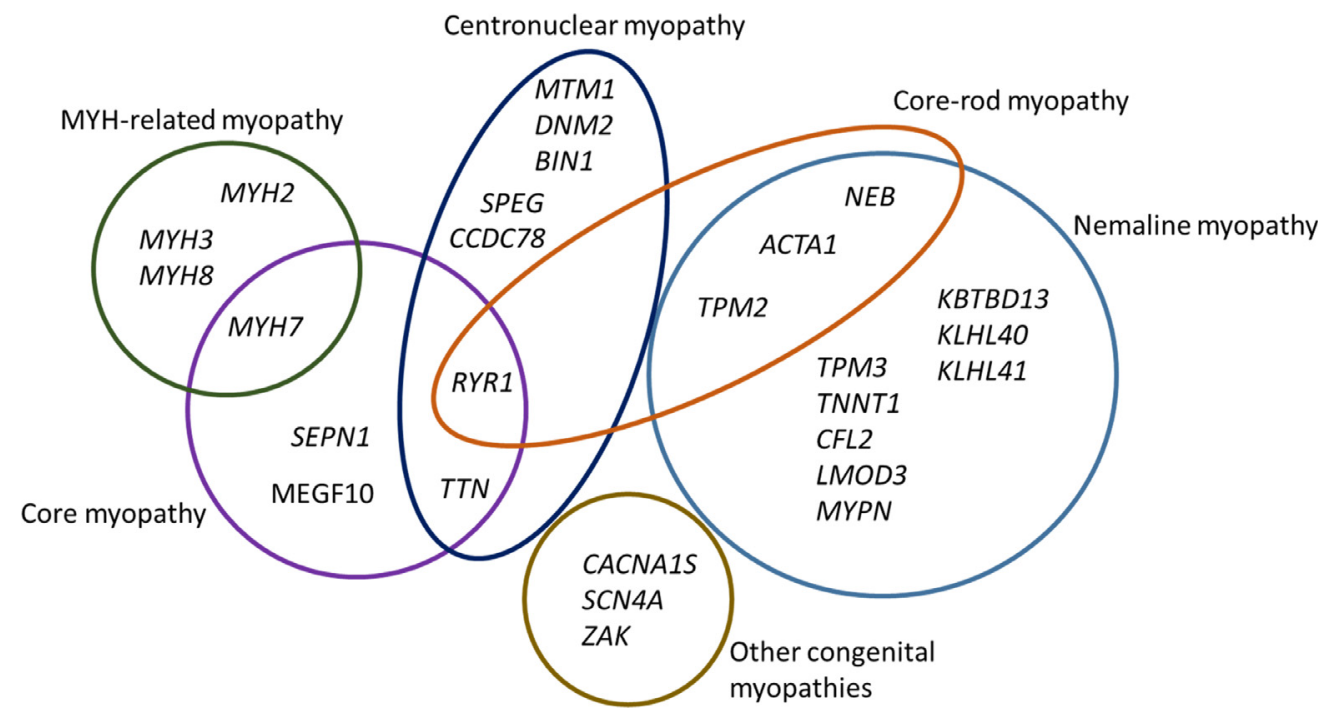

Figure Congenital myopathy-causing genes. The diagram shows 27 genes implicated in various forms of the congenital myopathies, and the overlap between different entities. Core-rod myopathy was included to illustrate the overlap between nemaline myopathy and core myopathy. 
Table Genes Causing Congenital Myopathies

\begin{tabular}{|c|c|c|c|}
\hline Disorder & Gene & Inheritance & Other Entities Caused by Mutations in the Gene \\
\hline \multirow[t]{11}{*}{ Nemaline myopathy } & NEB & $A R, A D^{*}$ & $\begin{array}{l}\text { Distal nebulin myopathy, distal nemaline myopathy, core-rod } \\
\text { myopathy, lethal multiple pterygium syndrome }\end{array}$ \\
\hline & ACTA1 & de novo, $A D, A R$ & $\begin{array}{l}\text { Actin-accumulation myopathy, core-rod myopathy, intranuclear } \\
\text { rod myopathy, zebra body myopathy, CFTD, progressive } \\
\text { scapuloperoneal myopathy, distal nemaline myopathy }\end{array}$ \\
\hline & TPM3 & $A D$, de novo, $A R$ & CFTD \\
\hline & TPM2 & $A D$, de novo, $A R^{+}$ & $\begin{array}{l}\text { CFTD, core-rod myopathy, distal arthrogryposis, Escobar } \\
\text { syndrome (AR) }\end{array}$ \\
\hline & TNNT1 & AR & \\
\hline & CFL2 & AR & \\
\hline & LMOD3 & AR & \\
\hline & MYPN & AR & Cardiomyopathy \\
\hline & KBTBD13 & $A D$ & \\
\hline & $K L H L 40$ & AR & \\
\hline & $K L H L 41$ & AR & \\
\hline \multirow[t]{5}{*}{ Core myopathy } & $R Y R 1$ & $A D, A R$ & $\begin{array}{l}\text { Core-rod myopathy, CFTD, malignant hyperthermia, } \\
\text { multi-minicore disease with ophthalmoplegia, arthrogryposis } \\
\text { multiplex congenita }\end{array}$ \\
\hline & SEPN1 & AR & $\begin{array}{l}\text { Rigid spine muscular dystrophy, CFTD, desmin-related myopathy } \\
\text { with Mallory body-like inclusions, myofibrillar myopathy }\end{array}$ \\
\hline & $T T N$ & AR & $\begin{array}{l}\text { TMD, LGMD2J, HMERF, adult-onset recessive proximal mus- } \\
\text { cular dystrophy, Emery-Dreifuss-like phenotype without } \\
\text { cardiomyopathy, cardiomyopathy }\end{array}$ \\
\hline & MYH7 & $A D$ & $\begin{array}{l}\text { Laing distal myopathy, CFTD, myosin storage myopathy } \\
\text { (hyaline body myopathy), cardiomyopathy }\end{array}$ \\
\hline & MEGF10 & AR & \\
\hline \multirow[t]{7}{*}{ Centronuclear myopathy } & MTM1 & X-linked & \\
\hline & DNM2 & $\mathrm{AD}$ & CMTDIB, CMT2M \\
\hline & $R Y R 1$ & AR & See above \\
\hline & BIN1 & $A R, A D$ & \\
\hline & $T T N$ & AR & See above \\
\hline & SPEG & AR & \\
\hline & $C C D C 78$ & AD & \\
\hline \multirow[t]{4}{*}{ MYH-related myopathy } & MYH2 & $A D, A R$ & \\
\hline & MYH7 & AD & See above \\
\hline & МYHз & $A D$ & Distal arthrogryposis \\
\hline & MYH8 & AD & Distal arthrogryposis \\
\hline \multirow{3}{*}{$\begin{array}{l}\text { Other congenital } \\
\text { myopathies }\end{array}$} & CACNA1S & $A D, A R$ & Hypokalemic periodic paralysis type 1 , malignant hyperthermia \\
\hline & SCN4A & AR & $\begin{array}{l}\text { Hypokalemic periodic paralysis type } 2 \text {, congenital myasthenic } \\
\text { syndrome } 16, \text { myotonia congenita, paramyotonia congenita }\end{array}$ \\
\hline & ZAK & AR & Split-foot malformation with mesoaxial polydactyly \\
\hline
\end{tabular}

AD, autosomal dominant; AR, autosomal recessive; CFTD, congenital fiber type disproportion; CMT, Charcot-Marie-Tooth neuropathy; HMERF, hereditary myopathy with early respiratory failure; LGMD, limb-girdle muscular dystrophy; TMD, tibial muscular dystrophy.

* Only 1 dominant NEB mutation has been identified to date.

${ }^{\dagger}$ Only 1 recessive TPM2 mutation has been identified to date.

2 or more generations have been identified in less than $5 \%$ of ACTA1 families, while mosaicism has been observed in a few families. ${ }^{32-34}$ We have recently described a dominant ACTA1 missense variant segregating in a 3-generation family with clinically variable NM, illustrating the clinical and histological variability of NM between patients sharing the same mutation.

In addition to NM, dominant, mostly de novo, disease-causing variants in ACTA1 can cause actin-accumulation myopathy, ${ }^{35}$ cap myopathy, ${ }^{36}$ congenital fiber type disproportion, ${ }^{37}$ core-rod myopathy, ${ }^{38}$ intranuclear rod myopathy, ${ }^{39,40}$ zebra body myopathy, ${ }^{41}$ progressive scapuloperoneal myopathy, ${ }^{42}$ and distal myopathy with nemaline rods. ${ }^{43}$

\section{The Alpha- and Beta-Tropomyosin Genes (TPM3 and TPM2)}

Mutations in TPM3 and TPM2 are relatively rare causes of NM, accounting for less than $10 \%$ of the cases. In addition to NM, mutations in TPM3 and TPM2 can cause cap myopathy, corerod myopathy, congenital fiber type disproportion, distal 
arthrogryposes, and Escobar syndrome. ${ }^{5}$ The majority of the mutations in both TPM3 and TPM2 are dominant missense variants or in-frame deletions removing one amino acid. A few recurrent mutations have been described in both genes; p.Lys7del and p.Glu139del in TPM2, and p.Arg168His, p.Arg168Cys, and p.Arg168Gly in TPM3. The mutations alter the conserved coiled-coil structure of the tropomyosins, resulting in aberrant tropomyosin-actin-binding. .,44 $^{-14}$

Recessive mutations are more common in TPM3 than in TPM2. In TPM2 only 1 recessive homozygous nonsense mutation has been described, causing Escobar syndrome associated with $\mathrm{NM} .^{45}$ In TPM3, a few recessive mutations, including nonsense, frameshift, and stop-lost mutations have been described ${ }^{46-49}$ NMs caused by mutations in TPM2 usually have milder presentations than NMs caused by mutations in TPM3. ${ }^{5}$ Recessive disease caused by mutations in these genes appears mostly to be severe. No clear correlation was found between the type of mutation and the clinical phenotype. Cap formation in the muscle biopsy may be seen in disorders caused by mutations in either gene, and type 1 fiber hypotrophy and predominance is common in both groups. ${ }^{5}$ Furthermore, we have identified a large, 17-21 kb homozygous deletion that removes the promoter and the first 2 exons of TPM3, causing a severe form of NM. ${ }^{2}$

\section{The Troponin T1 Gene (TNNT1)}

The first mutation in TNNT1, a recessive nonsense mutation causing a severe form of NM with tremor in the first months of life and contractures in the Old Order Amish, was described almost 20 years ago. ${ }^{18}$ Not until recently have a few other NM-causing mutations in TNNT1 been identified, all showing recessive inheritance. Compound heterozygosity for a splice site mutation resulting in skipping of TNNT1 exon 8, and an exon 14 deletion was identified in a Dutch patient with a similar clinical phenotype as in Amish NM. ${ }^{50}$ A clinical phenotype similar to Amish NM was also observed in a Hispanic patient homozygous for a nonsense mutation (different from the Amish one) in TNNT1 ${ }^{51}$ Homozygosity for a complex indel mutation in TNNT1 causing premature truncation of the protein has been described in 9 unrelated Palestinian patients with a severe form of NM. ${ }^{52}$

\section{The Cofilin-2 Gene (CFL2)}

Recessive mutations in the CFL2 gene are rare causes of NM. The first CFL2 mutation was described in 2007. The homozygous missense mutation, p.Ala35Thr, was found to cause NM with some minicores in a large consanguineous family of Middle Eastern origin showing congenital onset, delayed milestones and no facial weakness or foot drop. ${ }^{20}$ The second CFL2 mutation was published in 2012. Again a homozygous missense mutation, in this case p.Val7Met, was found in 2 sisters of Iraqi Kurdish origin with axial and limb girdle weakness who were born to consanguineous parents. The sisters had NM with features of myofibrillar myopathy. ${ }^{53}$ A third mutation described in CFL2 is a homozygous 4 base pair deletion causing a frameshift, p.Lys34Glnfs*6. The mutation had caused a severe form of NM in a Saudi Arabian consanguineous family. ${ }^{54}$

\section{The Leiomodin-3 Gene (LMOD3)}

Recessive mutations in LMOD3 have hitherto been described in 15 families with severe, often lethal forms of NM, which in some cases were associated with perinatal fractures. ${ }^{24,55}$ Most of the mutations are nonsense or frameshift variants causing loss of leiomodin-3 protein expression. The patients were homozygous or compound heterozygous for the mutations. ${ }^{24}$

\section{The Myopalladin Gene (MYPN)}

Recessive mutations in MYPN have been described in four families with childhood or adult-onset mild NM, and in 2 families with congenital slowly progressive cap myopathy. ${ }^{25,56}$ All MYPN mutations described to date are loss-of-function variants, either nonsense, frameshift or splice site variants, leading to no or very low expression of myopalladin in skeletal muscle. The patients are either homozygous or compound heterozygous for the mutations. Intranuclear rods, previously only associated with ACTA1 mutations, were observed in the muscle biopsies of 2 of the patients with mild NM. ${ }^{25}$ Interestingly, dominant MYPN mutations have been reported to cause dilated, familial hypertrophic or familial restrictive cardiomyopathy. ${ }^{57-59}$ Contrary to the NMand cap myopathy-causing mutations, the cardiomyopathycausing MYPN mutations lead to the expression of mutant proteins with dominant-negative effects in cardiomyocytes. ${ }^{58}$

\section{The Kelch Repeat- and BTB/POZ Domain- Containing Protein 13, the Kelch-Like 40 and the Kelch-Like 41 Genes (KBTBD13, $K L H L 40$, and $K L H L 41)$}

KBTBD13, KLHL40, and KLHL41 encode proteins of the Kelch superfamily including altogether 66 genes and 63 protein members. ${ }^{60}$ KBTBD 13 interacts with Cullin 3 ubiquitin ligase, and this interaction is required for the formation of a functional Cul3 RING ubiquitin ligase complex, which is involved in the ubiquitination of proteins destined for degradation. ${ }^{61}$ Three different missense variants, p.Arg248Ser, p.Lys390Asn, and p.Arg408Cys in KBTBD13 have been found to cause autosomal dominant NM with cores, and unusual clinical presentations including a characteristic slowness of movement. ${ }^{21}$

KLHL40 has been shown to bind and stabilize nebulin and LMOD3 in the sarcomere, as well as prevent ubiquitination of LMOD3. ${ }^{62}$ Recessive mutations in KLHL40 are a fairly common cause of severe NM, often with fetal akinesia or hypokinesia and contractures, fractures, respiratory failure, and swallowing difficulties at birth. Mutations in KLHL40 account for up to $28 \%$ of severe cases of NM in the Japanese population due to a founder mutation, p.Glu528Lys. ${ }^{22}$ One patient with a mild form of NM has been reported to be homozygous for a missense mutation, p.Arg500Cys, in KLHL40. ${ }^{63}$ This mutation has not been found in the severe cases published to date. ${ }^{22,64,65}$ Furthermore, one patient with severe NM due to compound heterozygous mutations in KLHL40 showed prolonged beneficial response to treatment with high-dose acetylcholinesterase inhibitors (pyridostigmine). ${ }^{66}$ Such a response 
has also been observed in other congenital myopathies, for example, myotubular/centronuclear myopathy. ${ }^{67}$

KLHL41 shows high homology to KLHL40, but KLHL41 preferentially stabilizes nebulin rather than LMOD3. ${ }^{68}$ Five families with clinically different forms of NM have been found to have recessive mutations in KLHL41. Frameshift mutations correlated with severe phenotypes with neonatal death, whereas missense variants resulted in impaired motor function with survival into late childhood and/or early adulthood compatible with mild, typical or intermediate NM. ${ }^{23}$

\section{Core Myopathies}

Central core disease, minicore myopathy, and multiminicore disease are historical definitions of congenital myopathies with cores, that is, areas devoid of mitochondria and, thus, lack of oxidative enzyme activity in muscle biopsies. There is pathologic, clinical and genetic overlap in congenital myopathies with cores, and thus the term "core myopathy" is nowadays preferentially used. ${ }^{11}$ Five genes have been reported to cause core myopathies. The ryanodine receptor 1 encoding gene, RYR1, was the first one to be discovered, ${ }^{69,70}$ and is now known as the major core myopathy-causing gene. ${ }^{71}$ The second most common core myopathy-causing gene, SEPN1 encodes selenoprotein $\mathrm{N}^{72}$ Occasional mutations causing core myopathies have also been described in the satellite cell gene MEGF10 ${ }^{73}$ the titin gene TTN ${ }^{74}$ and the myosin heavy chain encoding gene $\mathrm{MYH}^{75}$ (Fig., Table).

\section{The Ryanodine Receptor 1 Gene ( $R Y R 1)$}

RYR1 encodes the skeletal muscle specific ryanodine receptor RYR1, which is a calcium release channel involved in excitationcontraction coupling activating muscle contraction. Both dominant and recessive mutations in RYR1 have been found to cause core myopathies, but also related disorders such as core-rod myopathy, congenital FTD and centronuclear myopathy, as well as malignant hyperthermia susceptibility. ${ }^{6,76}$

RYR1 is a large gene with 106 exons encoding a polypeptide of 5037 amino acids, which forms the subunits of the tetramer calcium release channel. More than 200 RYR1 mutations have been reported. ${ }^{77,78}$ Most mutations causing core myopathies and malignant hyperthermia are dominant missense variants changing conserved amino acids, many of them clustered in specific hotspot regions in the N-terminus, central region and in the C-terminal transmembrane region of RYR1. ${ }^{71,76}$ De novo dominant RYR1 variants have been reported to cause core-rod myopathy. ${ }^{79-81}$

Recessive RYR1 mutations are widespread throughout the gene and patients with such mutations are generally more severely affected than those with a dominant mutation. . $^{8,83}$ The recessive mutations include null mutations, but also combinations of missense variants. Among the recessive variants, one recurrent allele carrying 3 different missense variants ( $p$. Ile1571Val, p.Arg3366His, and p.Tyr3933Cys) has been reported in the Dutch population, but it is unclear whether one of the variants is causative, or if a combination of 2 or all
3 variants cause disease. Furthermore, this 3 missense variantcarrying allele, as well as some other missense variants are associated with the malignant hyperthermia trait in heterozygous individuals, but cause recessive RYR1-related myopathies in homozygous or compound heterozygous individuals. ${ }^{83}$

In addition to variants affecting a single or a few base pairs, 2 recessive large-scale $R Y R 1$ deletions associated with myopathies have been published. ${ }^{84,85}$ The first one, an in-frame deletion of 54 out of 106 RYR1 exons, was identified in a child with a congenital myopathy with lethal neonatal weakness and atypical histopathologic features. The child was compound heterozygous for the deletion and a single amino acid duplication. ${ }^{84}$ The second large deletion starts in RYR1 exon 91 and ends within exon 98, causing a frameshift. The deletion was detected in a family with recessive late-onset core myopathy, the patients being compound heterozygous for the deletion and a missense variant. ${ }^{85}$ In addition, a recessive deletion of RYR1 exons 70-71 has been described in a family with severe arthrogryposis multiplex congenita. ${ }^{86}$

Tissue-specific epigenetic silencing of the maternal RYR1 allele has been documented in a cohort of patients with recessive core myopathies. Silencing of the maternal allele in skeletal muscle tissue unmasked the recessive paternal allele causing the disease. ${ }^{9}$

\section{The Selenoprotein N Gene (SEPN1)}

SEPN1 encodes selenoprotein N, which is an integral membrane glycoprotein of the endoplasmic reticulum. SEPN1 is expressed at high levels in several human fetal tissues, and is thought to have a role in early muscle development. ${ }^{87}$ SEPN1 is physically associated with ryanodine receptors and modifies RYR channel activity. ${ }^{88}$ Furthermore, it has recently been shown that SEPN1 is a key component of redoxregulated calcium metabolism in the endoplasmic reticulum, through its interaction with the SERCA2 calcium pump. ${ }^{89}$

Recessive loss-of-function mutations in SEPN1 have caused entities termed rigid spine muscular dystrophy, core myopathy, congenital fiber type disproportion, and desminrelated myopathy with Mallory body-like inclusions. ${ }^{72,90,91}$ Due to the overlap of clinical and histopathologic features these disorders are now collectively referred to as SEPN1related myopathies. All types of mutations have been identified in SEPN1, many being truncating nonsense or frameshift variants, but missense variants affecting conserved amino acids are also common. Homozygous mutations seem to be surprisingly prevalent, also in affected children born to nonconsanguineous parents. ${ }^{92,93}$

\section{The Multiple EGF-Like Domain 10 Gene (MEGF10)}

A recessive congenital myopathy with minicores has been described, caused by missense variants in MEGF10. Three siblings were compound heterozygous for 2 different missense variants, p.Cys326Arg and p.Cys774Arg in MEGF10. ${ }^{73}$ MEGF10 regulates myoblast function via the $\mathrm{NOTCH}$ signalling pathway, 
and the interaction between MEGF10 and NOTCHI is impaired by the p.Cys 774 Arg variant. ${ }^{94}$

\section{The Titin Gene (TTM)}

The huge TTN gene with 363 exons encodes titin, the largest polypeptide in nature. One titin molecule reaches from the $\mathrm{Z}$ disc to the $\mathrm{M}$ line in the skeletal and cardiac muscle sarcomeres. ${ }^{95,96}$ Given the size of titin, it is not surprising that several clinically distinct disorders affecting skeletal and/or cardiac muscle are caused by dominant or recessive mutations in TTN. ${ }^{8}$ Most of these disorders have adult onset. However, five patients from 2 families with congenital muscle weakness, minicore-like lesions and abundant centrally located nuclei, and severe childhood-onset dilated cardiomyopathy were found to be homozygous for truncating mutations in the C-terminus of TTN. The parents were consanguineous in both families. ${ }^{97}$ Furthermore, in a cohort of 31 patients with congenital core myopathy combined with primary heart disease, 7 pathogenic TTN variants were identified in 5 patients from 4 families. The variants included missense and truncating mutations. The patients were homozygous or compound heterozygous for the mutations. ${ }^{74}$

\section{The Myosin Heavy Chain 7 Gene (MYH7)}

The majority of the more than 500 missense mutations identified in the slow skeletal muscle fiber myosin heavy chain encoding gene MYH7 cause cardiomyopathy. ${ }^{98}$ A subset of the mutations cause skeletal muscle disease, including Laing distal myopathy and myosin storage myopathy. ${ }^{99}$ More recently mutations in MYH7 have been reported in dominant core myopathies. ${ }^{75,100}$ Cullup al. described 4 patients from 2 families affected by multiminicore disease caused by novel dominant missense mutations in $M Y H 77^{75}$ Romero et al described four patients in a 3-generation family with autosomal dominant central core disease. They identified a novel missense mutation in $\mathrm{MYH7}$ that segregated with the disease in the family. ${ }^{100}$ The mutations identified in these families are located in the MYH7 tail region, close to previously described mutations causing Laing distal myopathy.

\section{Centronuclear Myopathies}

Centrally located nuclei in the muscle fibers are hallmarks of centronuclear (myotubular) myopathies (CNM), but some muscle biopsies may also show additional pathological features such as type 1 fiber predominance, type 1 fiber hypotrophy, and cores. The most common genes causing centronuclear myopathies are MTM1, DNM2, RYR1, and TTN. Minor causative genes are BIN1, CCDC78, and SPEG ${ }^{11}$ (Fig., Table). RYR1 and TTN variants identified in CNM will be discussed briefly below. The other CNM genes will be the focus of separate paragraphs.

Mutations in RYR1 have turned out to be a fairly common cause of autosomal recessive CNM (ARCNM). The patients are usually compound heterozygous for 2 mutations, often one truncating mutation on one allele and a missense one on the other allele. The mutations are spread all across the RYR1 gene. Some of the RYR1 mutations found in ARCNM patients have previously been reported in core myopathy or malignant hyperthermia susceptibility. ${ }^{101-104}$

Compound heterozygous truncating mutations causing ARCNM have also been identified in the TTN gene. To date, 7 unrelated patients with ARCNM due to mutations in TTN have been described. ${ }^{103,105,106}$ The CNM-causing mutations are spread all along the TTN gene. One of the mutations has previously been reported to cause tibial muscular dystrophy, and another caused adult-onset cardiomyopathy in the heterozygous state. ${ }^{105}$

\section{The Myotubularin Gene (MTM1)}

Mutations in MTM1, encoding myotubularin, a ubiquitously expressed lipid phosphatase, cause X-linked myotubular myopathy (XLMTM). ${ }^{107}$ Myotubularin colocalizes with RYR1 at the junctional sarcoplasmic reticulum in skeletal muscle, and it is a key regulator of sarcoplasmic reticulum remodelling together with its lipid substrate phosphatidylinositol 3-monophosphate (PtdIns3P). Lack of MTM1 activity leads to disorganisation of the sarcoplasmic reticulum, which is considered to be the primary cause of most of the organelle positioning defects observed in muscles biopsies from XLMTM patients. ${ }^{108}$

The XLMTM-causing mutations in MTM1 are loss-of-function mutations spread across the 15 exons of the gene. The majority of the patients are neonatally severely affected boys. Most mutations are truncating, but missense variants affecting conserved amino acids essential for MTM1 activity are common also. ${ }^{109,110}$ A few large deletions removing one or more MTM1 exons, as well as whole-gene deletions of MTM1 including neighbouring genes have been reported. The latter causes contiguous gene syndromes. ${ }^{3,109}$ Several different types of MTM1 pre-mRNA splicing affecting mutations have also been described. ${ }^{109,111,112}$ Germ line mosaicism for de novo MTM1 mutations has been documented in a few families, in some cases manifesting as paternal transmission of the X-linked pathogenic variant. ${ }^{109,113}$

Evidence is accumulating that there is a higher number of females manifesting XLMTM than previously anticipated. ${ }^{3,114}$ Females with XLMTM are usually less severely affected than males, but the clinical phenotype is highly variable in age of onset and severity. The most severely affected females can show a similar clinical course as a severely affected XLMTM male. In general, those MTM1 mutations that cause a severe phenotype in males, cause a milder phenotype in females, probably due to the normal pattern of approximately 50-50 X-chromosome inactivation in females. However, there is an increased prevalence of highly skewed X-chromosome inactivation in females affected by XLMTM, although it has not been possible to determine which of the $\mathrm{X}$ chromosomes is preferentially inactivated. ${ }^{114}$ Not all manifesting females show any skew, even in muscle tissue.

Interestingly, dynamin 2 (DNM2) expression levels are increased in the muscles of XLMTM patients, as well as in MTM1 knock-out mice, indicating that MTM1 may be a 
negative regulator of DNM2 expression. ${ }^{115}$ This finding has led to the development of a potential therapeutic approach aiming towards reducing DNM2 levels in the muscles of XLMTM patients. Proof-of-principle has been achieved with antisense oligonucleotide-mediated DNM2 knockdown in a mouse model for XLMTM. ${ }^{116}$

\section{The Dynamin 2 Gene (DNM2)}

DNM2 encodes dynamin 2, a large GTPase involved in diverse cellular processes, among others endocytosis, cytokinesis, phagocytosis, and cell migration. Mutations in DNM2 cause autosomal dominant ADCNM with onset usually in adolescence or early childhood, with ptosis, distal weakness and contractures, and often radial strands in muscle fibers on biopsy, and Charcot-Marie-Tooth (CMT) peripheral neuropathy (CMTDIB and CMT2M). ${ }^{117-119}$ However, cases with earlier onset have been reported due to de novo mutations in the pleckstrin homology domain of DNM2. ${ }^{120}$ The ADCNM-causing mutations in DNM2 are gain-of -function mutations, predominantly missense variants. One in-frame deletion of one amino acid, as well as one splice site mutation causing an in-frame deletion of three amino acids in addition to an in-frame insertion of 23 new amino acids have been identified. Many of the missense variants are recurrent and present in several unrelated families. The mutations causing ADCNM are distinct from the ones causing CMT. ${ }^{119}$

Functional studies of common ADCNM DNM2 mutations show abnormal self-assembly of mutant DNM2 resulting in abnormally high GTPase activity of the protein, which in turn leads to T-tubule fragmentation. ${ }^{121}$ The hyperactive mutant DNM2 protein is a potential therapeutic target in ADCNM, that is, downregulation of DNM2 activity should have a similar beneficial effect in ADCNM muscle as in XLMTM muscle. ${ }^{116,121}$

\section{The Bridging Integrator 1 Gene (BIN1)}

BIN1 encodes for amphiphysin 2, a protein involved in membrane tubulation. The membrane tubulation activity of BIN1 is enhanced by its interaction with MTM1. ${ }^{122}$ Nicot et al described the first disease-causing variants in BIN1 10 years ago. Two missense variants and 1 nonsense variant were shown to cause ARCNM with congenital or childhood onset in 3 consanguineous families. The patients were homozygous for the mutations. ${ }^{123}$ Subsequently, 1 novel homozygous missense mutation and 1 novel homozygous nonsense mutation have been published as causative for ARCNM. ${ }^{124,125}$ Furthermore, a homozygous acceptor splice site mutation in intron 10 causing abnormal splicing of the skeletal musclespecific BIN1 exon 11 was identified in patients with rapidly progressive ARCNM in 1 consanguineous family. The corresponding splice site was found to be mutated in canine Inherited Myopathy of Great Danes, which, thus, represents a mammalian model for BIN1-related CNM. ${ }^{126}$

Dominant mutations in BIN1 have been reported to cause mild and adult-onset forms of CNM. ${ }^{127,128}$ Three of the mutations are single base pair deletions in the stop codon of
BIN1, causing read-through and extension of the protein with 52 novel amino acids. Two other dominant mutations were 1 in-frame deletion of 1 amino acid, and 1 missense mutation, located in the N-terminus of BIN $1 .{ }^{127}$ A second dominant missense mutation, also in the N-terminus, was recently published. ${ }^{128}$ The dominant BIN1 mutations are distinct from the recessive ones, with different impacts on protein function, suggesting different pathomechanisms for dominant and recessive BIN1-related CNM. ${ }^{127}$

\section{The SPEG Complex Locus Gene (SPEG)}

SPEG interacts with myotubularin at the junctional sarcoplasmic reticulum in skeletal muscle. SPEG is also expressed in cardiac muscle. The first SPEG mutations were described in $6 \mathrm{CNM}$ patients from 3 families. In addition to CNM, 2 unrelated patients had dilated cardiomyopathy. The mutations were recessive loss-of-function mutations (nonsense or frameshifts), and the patients were compound heterozygous or homozygous for the mutations. ${ }^{129}$ Two novel SPEG mutations were recently reported in 2 unrelated CNM patients. One of the patients had dilated cardiomyopathy also. The patient with CNM and cardiomyopathy was homozygous for a nonsense mutation, and the patient with CNM without cardiac involvement was homozygous for a frameshift mutation in SPEG. ${ }^{130}$

\section{The Coiled-Coil Domain-Containing Protein 78 Gene (CCDC78)}

Only 1 dominant mutation in CCDC78 causing CNM with atypical cores has been described in 1 family with patients in 3 generations. The mutation changes the acceptor splice site of intron 1 in CCDC78, causing retention of the intron, which is in-frame with the coding sequence. This is predicted to result in the addition of 74 amino acids to the protein. ${ }^{131}$

\section{Myosin-Related Myopathies}

Myosin heavy-chain genes, especially MYH7, MYH2, MYH3, and MYH8 are implicated in various myopathies affecting skeletal and/or cardiac muscle (Fig., Table). Some of these myopathies are congenital. MYH7 was already discussed in the context of the core myopathies, but dominant mutations in MYH7 can also cause, for example, congenital fiber type disproportion without any other specific histological features. One such case was recently reported to be due to a de novo heterozygous splice site mutation causing skipping of MYH7 exon 38. ${ }^{132} \mathrm{~A}$ few cases of MYH7-related congenital myopathy were also found in a cohort of Italian patients. These patients had dominant missense mutations in MYH7. ${ }^{133}$

Both dominant and recessive mutations in MYH2 can cause a usually mild congenital myopathy with external ophthalmoplegia. The dominant cases are caused by missense mutations, and the recessive ones usually by truncating mutations in $\mathrm{MYH} 2{ }^{7}$ A homozygous splice site mutation causing skipping of MYH2 exon 12, leading to a frameshift, 
was recently reported in a consanguineous family where 4 patients had a congenital myopathy with ophthalmoplegia. ${ }^{134}$ A novel homozygous frameshift mutation in MYH2 has also recently been described to cause a congenital myopathy with chronic aspiration pneumonia in infancy. ${ }^{135}$

MYH3 and MYH8 encode embryonic and fetal myosin heavy-chain isoforms. Dominant missense mutations in MYH3 and MYH8 cause distal arthrogryposis syndromes, probably as the result of a severe muscle weakness already during fetal development. ${ }^{7,136,137}$

\section{Other Genes Causing Congenital Myopathies}

Two genes, CACNA1S and SCN4A, previously known channelopathy-causing genes, have now been implicate in congenital myopathies as well. ${ }^{138-141}$ A third gene, ZAK, has also recently been identified as a novel congenital myopathy-causing gene ${ }^{142}$ (Fig., Table).

A dihydropyridine receptor (DHPR) congenital myopathy caused by dominant or recessive mutations in the CACNA1S gene was recently described in 11 patients from 7 families. The muscle biopsies showed features of centralised nuclei, focal zones of sarcomeric disorganisation, and cores. DHPR directly regulates the RYR1 calcium release channel. Both the dominant and recessive mutations identified in CACNA1S are hypothesised to cause a decrease in overall DHPR function in skeletal muscle. ${ }^{138}$

Recessive loss-of-function mutations in the SCN4A gene encoding the alpha-subunit of the skeletal muscle voltage-gated sodium channel $\left(\mathrm{Na}_{\mathrm{v}} 1.4\right)$ have been identified in patients from 8 families with a congenital myopathy of variable severity, severe or "classical." Histological features were unspecific; abnormal fiber size variability, in some with type 1 predominance, and no pathognomic findings. ${ }^{139-141}$ Partial loss-of-function mutations were associated with a milder disease phenotype. ${ }^{140}$

A congenital myopathy with fiber type disproportion caused by recessive loss-of-function mutations in the mitogen-activated protein triple kinase encoding gene, ZAK, was recently reported in six patients from three families. The patients were homozygous for frameshift or nonsense mutations in ZAK. The parents were consanguineous in all families. All mutations are located in the kinase domain of ZAK. ${ }^{142}$ Interestingly, in 2 families recessive mutations in the SAM domain of ZAK have been associated with split-foot malformation with mesoaxial polydactyly. ${ }^{143}$

\section{Conclusions}

Here we have described 27 different genes implicated in various forms of the congenital myopathies. It is clear that the number of genes will increase due to the accelerated use of next-generation sequencing methods. Moreover, large CNVs and rearrangements are likely to be discovered as causative mutation types in many more disorders than those currently known.

\section{References}

1. Kiiski K, Laari L, Lehtokari VL, et al: Targeted array comparative genomic hybridization-A new diagnostic tool for the detection of large copy number variations in nemaline myopathy-causing genes. Neuromuscul Disord 23:56-65, 2013

2. Kiiski K, Lehtokari VL, Manzur AY, et al: A large deletion affecting TPM3, causing severe nemaline myopathy. J Neuromuscul Dis 2:433438,2015

3. Savarese M, Musumeci $O$, Giugliano T, et al: Novel findings associated with MTMl suggest a higher number of female symptomatic carriers. Neuromuscul Disord 26:292-299, 2016

4. Nowak KJ, Ravenscroft G, Laing NG: Skeletal muscle alpha-actin diseases (actinopathies): Pathology and mechanisms. Acta Neuropathol $125: 19-32,2013$

5. Marttila M, Lehtokari VL, Marston S, et al: Mutation update and genotype-phenotype correlations of novel and previously described mutations in TPM2 and TPM3 causing congenital myopathies. Hum Mutat 35:779-790, 2014

6. Hwang JH, Zorzato F, Clarke NF, et al: Mapping domains and mutations on the skeletal muscle ryanodine receptor channel. Trends Mol Med 18:644-657, 2012

7. Tajsharghi H, Oldfors A: Myosinopathies: Pathology and mechanisms. Acta Neuropathol 125:3-18, 2013

8. Savarese M, Sarparanta J, Vihola A, et al: Increasing role of titin mutations in neuromuscular disorders. J Neuromuscul Dis 3:293-308, 2016

9. Zhou H, Brockington M, Jungbluth H, et al: Epigenetic allele silencing unveils recessive RYRl mutations in core myopathies. Am J Hum Genet 79:859-868, 2006

10. Rokach O, Sekulic-Jablanovic M, Voermans N, et al: Epigenetic changes as a common trigger of muscle weakness in congenital myopathies. Hum Mol Genet 24:4636-4647, 2015

11. Sewry CA, Wallgren-Pettersson C: Myopathology in congenital myopathies. Neuropathol Appl Neurobiol 43:5-23, 2017

12. Lehtokari VL, Kiiski K, Sandaradura SA, et al: Mutation update: The spectra of nebulin variants and associated myopathies. Hum Mutat 35:1418-1426, 2014

13. Lehtokari VL, Ceuterick-de Groote C, de Jonghe P, et al: Cap disease caused by heterozygous deletion of the beta-tropomyosin gene TPM2. Neuromuscul Disord 17:433-442, 2007

14. Tajsharghi H, Ohlsson M, Lindberg C, et al: Congenital myopathy with nemaline rods and cap structures caused by a mutation in the betatropomyosin gene (TPM2). Arch Neurol 64:1334-1338, 2007

15. Laing NG, Wilton SD, Akkari PA, et al: A mutation in the alpha tropomyosin gene TPM3 associated with autosomal dominant nemaline myopathy NEMI. Nat Genet 249:75-79, 1995

16. Nowak KJ, Wattanasirichaigoon D, Goebel HH, et al: Mutations in the skeletal muscle alpha-actin gene in patients with actin myopathy and nemaline myopathy. Nat Genet 23:208-212, 1999

17. Pelin K, Hilpela P, Donner K, et al: Mutations in the nebulin gene associated with autosomal recessive nemaline myopathy. Proc Natl Acad Sci U S A 96:2305-2310, 1999

18. Johnston JJ, Kelley RI, Crawford TO, et al: A novel nemaline myopathy in the Amish caused by a mutation in troponin Tl. Am J Hum Genet 67:814-821, 2000

19. Donner K, Ollikainen M, Ridanpaa M, et al: Mutations in the betatropomyosin (TPM2) gene-A rare cause of nemaline myopathy. Neuromuscul Disord 12:151-158, 2002

20. Agrawal PB, Greenleaf RS, Tomczak KK, et al: Nemaline myopathy with minicores caused by mutation of the CFL2 gene encoding the skeletal muscle actin-binding protein, cofilin-2. Am J Hum Genet 80:162-167, 2007

21. Sambuughin N, Yau KS, Olive M, et al: Dominant mutations in KBTBD13, a member of the BTB/Kelch family, cause nemaline myopathy with cores. Am J Hum Genet 87:842-847, 2010

22. Ravenscroft G, Miyatake S, Lehtokari VL, et al: Mutations in KLHL40 are a frequent cause of severe autosomal-recessive nemaline myopathy. Am J Hum Genet 93:6-18, 2013

23. Gupta VA, Ravenscroft G, Shaheen R, et al: Identification of KLHL41 mutations implicates BTB-Kelch-mediated ubiquitination as an 
alternate pathway to myofibrillar disruption in nemaline myopathy. Am J Hum Genet 93:1108-1117, 2013

24. Yuen M, Sandaradura SA, Dowling JJ, et al: Leiomodin-3 dysfunction results in thin filament disorganization and nemaline myopathy. J Clin Invest 124:4693-4708, 2014

25. Miyatake S, Mitsuhashi S, Hayashi YK, et al: Biallelic mutations in MYPN, encoding myopalladin, are associated with childhood-onset, slowly progressive nemaline myopathy. Am J Hum Genet 100:169-178, 2017

26. Kiiski K, Lehtokari VL, Loytynoja A, et al: A recurrent copy number variation of the NEB triplicate region: Only revealed by the targeted nemaline myopathy CGH array. Eur J Hum Genet 24:574-580, 2016

27. Marttila M, Hanif M, Lemola E, et al: Nebulin interactions with actin and tropomyosin are altered by disease-causing mutations. Skelet Muscle 4, 2014. 15-5040-4-15. eCollection 2014

28. Wallgren-Petterson C, Lehtokari VL, Kalimo H, et al: Distal myopathy caused by homozygous missense mutations in the nebulin gene. Brain 130:1465-1476, 2007

29. Romero NB, Lehtokari VL, Quijano-Roy S, et al: Core-rod myopathy caused by mutations in the nebulin gene. Neurology 73:1159-1161, 2009

30. Lehtokari VL, Pelin K, Herczegfalvi A, et al: Nemaline myopathy caused by mutations in the nebulin gene may present as a distal myopathy. Neuromuscul Disord 21:556-562, 2011

31. Abdalla E, Ravenscroft G, Zayed L, et al: Lethal multiple pterygium syndrome: A severe phenotype associated with a novel mutation in the nebulin gene. Neuromuscul Disord 27:537-541, 2017

32. Laing NG, Dye DE, Wallgren-Pettersson C, et al: Mutations and polymorphisms of the skeletal muscle alpha-actin gene (ACTA1). Hum Mutat 30:1267-1277, 2009

33. Witting N, Werlauff U, Duno M, et al: Prevalence and phenotypes of congenital myopathy due to alpha-actin 1 gene mutations. Muscle Nerve 53:388-393, 2016

34. Seidahmed MZ, Salih MA, Abdelbasit OB, et al: Gonadal mosaicism for ACTAl gene masquerading as autosomal recessive nemaline myopathy. Am J Med Genet A 170:2219-2221, 2016

35. Sparrow JC, Nowak KJ, Durling HJ, et al: Muscle disease caused by mutations in the skeletal muscle alpha-actin gene (ACTA1). Neuromuscul Disord 13:519-531, 2003

36. Hung RM, Yoon G, Hawkins CE, et al: Cap myopathy caused by a mutation of the skeletal alpha-actin gene ACTA1. Neuromuscul Disord 20:238-240, 2010

37. Laing NG, Clarke NF, Dye DE, et al: Actin mutations are one cause of congenital fibre type disproportion. Ann Neurol 56:689-694, 2004

38. Kaindl AM, Ruschendorf F, Krause S, et al: Missense mutations of ACTAl cause dominant congenital myopathy with cores. J Med Genet 41:842-848, 2004

39. Goebel HH, Warlo I: Nemaline myopathy with intranuclear rods-Intranuclear rod myopathy. Neuromuscul Disord 7:13-19, 1997

40. Domazetovska A, Ilkovski B, Kumar V, et al: Intranuclear rod myopathy: Molecular pathogenesis and mechanisms of weakness. Ann Neurol 62:597-608, 2007

41. Sewry CA, Holton JL, Dick DJ, et al: Zebra body myopathy is caused by a mutation in the skeletal muscle actin gene (ACTA1). Neuromuscul Disord 25:388-391, 2015

42. Zukosky K, Meilleur K, Traynor BJ, et al: Association of a novel ACTAl mutation with a dominant progressive scapuloperoneal myopathy in an extended family. JAMA Neurol 72:689-698, 2015

43. Liewluck T, Sorenson EJ, Walkiewicz MA, et al: Autosomal dominant distal myopathy due to a novel ACTAl mutation. Neuromuscul Disord $27: 742-746,2017$

44. Marttila M, Lemola E, Wallefeld W, et al: Abnormal actin binding of aberrant beta-tropomyosins is a molecular cause of muscle weakness in TPM2-related nemaline and cap myopathy. Biochem J 442:231239,2012

45. Monnier N, Lunardi J, Marty I, et al: Absence of beta-tropomyosin is a new cause of Escobar syndrome associated with nemaline myopathy. Neuromuscul Disord 19:118-123, 2009

46. Tan P, Briner J, Boltshauser E, et al: Homozygosity for a nonsense mutation in the alpha-tropomyosin slow gene TPM3 in a patient with severe infantile nemaline myopathy. Neuromuscul Disord 9:573-579, 1999
47. Wattanasirichaigoon D, Swoboda KJ, Takada F, et al: Mutations of the slow muscle alpha-tropomyosin gene, TPM3, are a rare cause of nemaline myopathy. Neurology 59:613-617, 2002

48. Lawlor MW, Dechene ET, Roumm E, et al: Mutations of tropomyosin 3 (TPM3) are common and associated with type 1 myofiber hypotrophy in congenital fiber type disproportion. Hum Mutat 31:176-183, 2010

49. Lehtokari VL, Pelin K, Donner K, et al: Identification of a founder mutation in TPM3 in nemaline myopathy patients of Turkish origin. Eur J Hum Genet 16:1055-1061, 2008

50. van der Pol WL, Leijenaar JF, Spliet WG, et al: Nemaline myopathy caused by TNNT1 mutations in a Dutch pedigree. Mol Genet Genomic Med 2:134-137, 2014

51. Marra JD, Engelstad KE, Ankala A, et al: Identification of a novel nemaline myopathy-causing mutation in the troponin Tl (TNNT1) gene: A case outside of the old order Amish. Muscle Nerve 51:767-772, 2015

52. Abdulhaq UN, Daana M, Dor T, et al: Nemaline body myopathy caused by a novel mutation in troponin Tl (TNNT1). Muscle Nerve 53:564-569, 2016

53. Ockeloen CW, Gilhuis HJ, Pfundt R, et al: Congenital myopathy caused by a novel missense mutation in the CFL2 gene. Neuromuscul Disord 22:632-639, 2012

54. Ong RW, AlSaman A, Selcen D, et al: Novel cofilin-2 (CFL2) four base pair deletion causing nemaline myopathy. J Neurol Neurosurg Psychiatry 85:1058-1060, 2014

55. Abbott M, Jain M, Pferdehirt R, et al: Neonatal fractures as a presenting feature of LMOD3-associated congenital myopathy. Am J Med Genet 173A:2789-2794, 2017

56. Lornage X, Malfatti E, Cheraud C, et al: Recessive MYPN mutations cause cap myopathy with occasional nemaline rods. Ann Neurol 81:467-473, 2017

57. Duboscq-Bidot L, Xu P, Charron P, et al: Mutations in the Z-band protein myopalladin gene and idiopathic dilated cardiomyopathy. Cardiovasc Res 77:118-125, 2008

58. Purevjav E, Arimura T, Augustin S, et al: Molecular basis for clinical heterogeneity in inherited cardiomyopathies due to myopalladin mutations. Hum Mol Genet 21:2039-2053, 2012

59. Meyer T, Ruppert V, Ackermann S, et al: Novel mutations in the sarcomeric protein myopalladin in patients with dilated cardiomyopathy. Eur J Hum Genet 21:294-300, 2013

60. Gupta VA, Beggs AH: Kelch proteins: Emerging roles in skeletal muscle development and diseases. Skelet Muscle 4, 2014. 11-5040-4-11. eCollection 2014

61. Sambuughin N, Swietnicki W, Techtmann S, et al: KBTBD13 interacts with Cullin 3 to form a functional ubiquitin ligase. Biochem Biophys Res Commun 421:743-749, 2012

62. Garg A, O'Rourke J, Long C, et al: KLHL40 deficiency destabilizes thin filament proteins and promotes nemaline myopathy. J Clin Invest $124: 3529-3539,2014$

63. Seferian AM, Malfatti E, Bosson C, et al: Mild clinical presentation in KLHL40-related nemaline myopathy (NEM 8). Neuromuscul Disord 26:712-716, 2016

64. Chen TH, Tian X, Kuo PL, et al: Identification of KLHL40 mutations by targeted next-generation sequencing facilitated a prenatal diagnosis in a family with three consecutive affected fetuses with fetal akinesia deformation sequence. Prenat Diagn 36:1135-1138, 2016

65. Todd EJ, Yau KS, Ong R, et al: Next generation sequencing in a large cohort of patients presenting with neuromuscular disease before or at birth. Orphanet J Rare Dis 10, 2015. 148-015-0364-0

66. Natera-de Benito D, Nascimento A, Abicht A, et al: KLHL40-related nemaline myopathy with a sustained, positive response to treatment with acetylcholinesterase inhibitors. J Neurol 263:517-523, 2016

67. Robb SA, Sewry CA, Dowling JJ, et al: Impaired neuromuscular transmission and response to acetylcholinesterase inhibitors in centronuclear myopathies. Neuromuscul Disord 21:379-386, 2011

68. Ramirez-Martinez A, Cenik BK, Bezprozvannaya S, et al: KLHL4l stabilizes skeletal muscle sarcomeres by nonproteolytic ubiquitination. Elife 6. https://doi.org/10.7554/eLife.26439, 2017

69. Quane KA, Healy JM, Keating KE, et al: Mutations in the ryanodine receptor gene in central core disease and malignant hyperthermia. Nat Genet 5:51-55, 1993 
70. Zhang Y, Chen HS, Khanna VK, et al: A mutation in the human ryanodine receptor gene associated with central core disease. Nat Genet 5:46-50, 1993

71. McCarthy TV, Quane KA, Lynch PJ: Ryanodine receptor mutations in malignant hyperthermia and central core disease. Hum Mutat 15: 410-417, 2000

72. Ferreiro A, Quijano-Roy S, Pichereau C, et al: Mutations of the selenoprotein $\mathrm{N}$ gene, which is implicated in rigid spine muscular dystrophy, cause the classical phenotype of multiminicore disease: Reassessing the nosology of early-onset myopathies. Am J Hum Genet 71:739-749, 2002

73. Boyden SE, Mahoney LJ, Kawahara G, et al: Mutations in the satellite cell gene MEGF10 cause a recessive congenital myopathy with minicores. Neurogenetics 13:115-124, 2012

74. Chauveau C, Bonnemann CG, Julien C, et al: Recessive TTN truncating mutations define novel forms of core myopathy with heart disease. Hum Mol Genet 23:980-991, 2014

75. Cullup T, Lamont PJ, Cirak S, et al: Mutations in MYH7 cause Multiminicore Disease $(\mathrm{MmD})$ with variable cardiac involvement. Neuromuscul Disord 22:1096-1104, 2012

76. Davis MR, Haan E, Jungbluth H, et al: Principal mutation hotspot for central core disease and related myopathies in the C-terminal transmembrane region of the RYR1 gene. Neuromuscul Disord 13:151-157, 2003

77. Jungbluth H, Sewry CA, Muntoni F: Core myopathies. Semin Pediatr Neurol 18:239-249, 2011

78. Lillis S, Abbs S, Mueller CR, et al: Clinical utility gene card for: Central core disease. Eur J Hum Genet 20. https://doi.org/10.1038/ ejhg.2011.179, 2012. Epub 2011 Oct 12

79. Scacheri PC, Hoffman EP, Fratkin JD, et al: A novel ryanodine receptor gene mutation causing both cores and rods in congenital myopathy. Neurology 55:1689-1696, 2000

80. von der Hagen M, Kress W, Hahn G, et al: Novel RYRl missense mutation causes core rod myopathy. Eur J Neurol 15:e31-e32, 2008

81. Hernandez-Lain A, Husson I, Monnier N, et al: De novo RYRl heterozygous mutation (I4898T) causing lethal core-rod myopathy in twins. Eur J Med Genet 54:29-33, 2011

82. Zhou H, Jungbluth H, Sewry CA, et al: Molecular mechanisms and phenotypic variation in RYRl-related congenital myopathies. Brain $130: 2024-2036,2007$

83. Snoeck M, van Engelen BG, Kusters B, et al: RYR1-related myopathies: A wide spectrum of phenotypes throughout life. Eur J Neurol 22: 1094-1112, 2015

84. Monnier N, Laquerriere A, Marret S, et al: First genomic rearrangement of the RYRl gene associated with an atypical presentation of lethal neonatal hypotonia. Neuromuscul Disord 19:680-684, 2009

85. Remiche G, Kadhim H, Abramowicz M, et al: A novel large deletion in the RYRl gene in a Belgian family with late-onset and recessive core myopathy. Neuromuscul Disord 25:397-402, 2015

86. Laquerriere A, Maluenda J, Camus A, et al: Mutations in CNTNAPI and ADCY6 are responsible for severe arthrogryposis multiplex congenita with axoglial defects. Hum Mol Genet 23:2279-2289, 2014

87. Petit N, Lescure A, Rederstorff M, et al: Selenoprotein N: An endoplasmic reticulum glycoprotein with an early developmental expression pattern. Hum Mol Genet 12:1045-1053, 2003

88. Jurynec MJ, Xia R, Mackrill JJ, et al: Selenoprotein N is required for ryanodine receptor calcium release channel activity in human and zebrafish muscle. Proc Natl Acad Sci U S A 105:12485-12490, 2008

89. Marino M, Stoilova T, Giorgi C, et al: SEPN1, an endoplasmic reticulum-localized selenoprotein linked to skeletal muscle pathology, counteracts hyperoxidation by means of redox-regulating SERCA2 pump activity. Hum Mol Genet 24:1843-1855, 2015

90. Ferreiro A, Ceuterick-de Groote C, Marks JJ, et al: Desmin-related myopathy with Mallory body-like inclusions is caused by mutations of the selenoprotein N gene. Ann Neurol 55:676-686, 2004

91. Clarke NF, Kidson W, Quijano-Roy S, et al: SEPN1: Associated with congenital fiber-type disproportion and insulin resistance. Ann Neurol 59:546-552, 2006

92. Scoto M, Cirak S, Mein R, et al: SEPN1-related myopathies: Clinical course in a large cohort of patients. Neurology 76:2073-2078, 2011
93. Ardissone A, Bragato C, Blasevich F, et al: SEPN1-related myopathy in three patients: Novel mutations and diagnostic clues. Eur J Pediatr $175: 1113-1118,2016$

94. Saha M, Mitsuhashi S, Jones MD, et al: Consequences of MEGF10 deficiency on myoblast function and Notchl interactions. Hum Mol Genet 26:2984-3000, 2017

95. Kolmerer B, Witt CC, Freiburg A, et al: The titin cDNA sequence and partial genomic sequences: Insights into the molecular genetics, cell biology and physiology of the titin filament system. Rev Physiol Biochem Pharmacol 138:19-55, 1999

96. Bang ML, Centner T, Fornoff F, et al: The complete gene sequence of titin, expression of an unusual approximately $700-\mathrm{kDa}$ titin isoform, and its interaction with obscurin identify a novel Z-line to I-band linking system. Circ Res 89:1065-1072, 2001

97. Carmignac V, Salih MA, Quijano-Roy S, et al: C-terminal titin deletions cause a novel early-onset myopathy with fatal cardiomyopathy. Ann Neurol 61:340-351, 2007

98. Colegrave M, Peckham M: Structural implications of beta-cardiac myosin heavy chain mutations in human disease. Anat Rec (Hoboken) 297:1670-1680, 2014

99. Lamont PJ, Udd B, Mastaglia FL, et al: Laing early onset distal myopathy: Slow myosin defect with variable abnormalities on muscle biopsy. J Neurol Neurosurg Psychiatry 77:208-215, 2006

100. Romero NB, Xie T, Malfatti E, et al: Autosomal dominant eccentric core disease caused by a heterozygous mutation in the MYH7 gene. J Neurol Neurosurg Psychiatry 85:1149-1152, 2014

101. Wilmshurst JM, Lillis S, Zhou H, et al: RYRl mutations are a common cause of congenital myopathies with central nuclei. Ann Neurol 68:717-726, 2010

102. Bevilacqua JA, Monnier N, Bitoun M, et al: Recessive RYRl mutations cause unusual congenital myopathy with prominent nuclear internalization and large areas of myofibrillar disorganization. Neuropathol Appl Neurobiol 37:271-284, 2011

103. Fattori F, Maggi L, Bruno C, et al: Centronuclear myopathies: Genotype-phenotype correlation and frequency of defined genetic forms in an Italian cohort. J Neurol 262:1728-1740, 2015

104. Abath Neto O, Moreno CAM, Malfatti E, et al: Common and variable clinical, histological, and imaging findings of recessive RYR1-related centronuclear myopathy patients. Neuromuscul Disord 27:975-985, 2017

105. Ceyhan-Birsoy O, Agrawal PB, Hidalgo C, et al: Recessive truncating titin gene, TTN, mutations presenting as centronuclear myopathy. Neurology 81:1205-1214, 2013

106. Witting N, Werlauff U, Duno M, et al: Phenotypes, genotypes, and prevalence of congenital myopathies older than 5 years in Denmark. Neurol Genet 3:el40, 2017

107. Laporte J, Hu LJ, Kretz C, et al: A gene mutated in X-linked myotubular myopathy defines a new putative tyrosine phosphatase family conserved in yeast. Nat Genet 13:175-182, 1996

108. Amoasii L, Hnia K, Chicanne G, et al: Myotubularin and PtdIns3P remodel the sarcoplasmic reticulum in muscle in vivo. J Cell Sci $126: 1806-1819,2013$

109. Laporte J, Biancalana V, Tanner SM, et al: MTM1 mutations in X-linked myotubular myopathy. Hum Mutat 15:393-409, 2000

110. Longo G, Russo S, Novelli G, et al: Mutation spectrum of the MTMI gene in XLMTM patients: 10 years of experience in prenatal and postnatal diagnosis. Clin Genet 89:93-98, 2016

111. Tanner SM, Schneider V, Thomas NS, et al: Characterization of 34 novel and six known MTMl gene mutations in 47 unrelated X-linked myotubular myopathy patients. Neuromuscul Disord 9:41-49, 1999

112. Al-Hashim A, Gonorazky HD, Amburgey K, et al: A novel intronic mutation in MTMl detected by RNA analysis in a case of X-linked myotubular myopathy. Neurol Genet 3:e182, 2017

113. Hedberg-Oldfors C, Visuttijai K, Topa A, et al: Grand paternal inheritance of X-linked myotubular myopathy due to mosaicism, and identification of necklace fibers in an asymptomatic male. Neuromuscul Disord 27:843-847, 2017

114. Biancalana V, Scheidecker S, Miguet M, et al: Affected female carriers of MTMl mutations display a wide spectrum of clinical and 
pathological involvement: Delineating diagnostic clues. Acta Neuropathol 2017. in press

115. Cowling BS, Chevremont T, Prokic I, et al: Reducing dynamin 2 expression rescues X-linked centronuclear myopathy. J Clin Invest $124: 1350-1363,2014$

116. Tasfaout H, Buono S, Guo S, et al: Antisense oligonucleotide-mediated Dnm2 knockdown prevents and reverts myotubular myopathy in mice. Nat Commun 8:15661, 2017

117. Bitoun M, Maugenre S, Jeannet PY, et al: Mutations in dynamin 2 cause dominant centronuclear myopathy. Nat Genet 37:1207-1209, 2005

118. Zuchner S, Noureddine M, Kennerson M, et al: Mutations in the pleckstrin homology domain of dynamin 2 cause dominant intermediate Charcot-Marie-Tooth disease. Nat Genet 37:289-294, 2005

119. Bohm J, Biancalana V, Dechene ET, et al: Mutation spectrum in the large GTPase dynamin 2, and genotype-phenotype correlation in autosomal dominant centronuclear myopathy. Hum Mutat 33:949-959, 2012

120. Bitoun M, Bevilacqua JA, Prudhon B, et al: Dynamin 2 mutations cause sporadic centronuclear myopathy with neonatal onset. Ann Neurol 62:666-670, 2007

121. Chin YH, Lee A, Kan HW, et al: Dynamin-2 mutations associated with centronuclear myopathy are hypermorphic and lead to T-tubule fragmentation. Hum Mol Genet 24:5542-5554, 2015

122. Royer B, Hnia K, Gavriilidis C, et al: The myotubularin-amphiphysin 2 complex in membrane tubulation and centronuclear myopathies. EMBO Rep 14:907-915, 2013

123. Nicot AS, Toussaint A, Tosch V, et al: Mutations in amphiphysin 2 (BIN1) disrupt interaction with dynamin 2 and cause autosomal recessive centronuclear myopathy. Nat Genet 39:1134-1139, 2007

124. Claeys KG, Maisonobe T, Bohm J, et al: Phenotype of a patient with recessive centronuclear myopathy and a novel BIN1 mutation. Neurology 74:519-521, 2010

125. Bohm J, Yis U, Ortac R, et al: Case report of intrafamilial variability in autosomal recessive centronuclear myopathy associated to a novel BIN1 stop mutation. Orphanet J Rare Dis 5, 2010. 35-1172-5-35

126. Bohm J, Vasli N, Maurer M, et al: Altered splicing of the BIN1 musclespecific exon in humans and dogs with highly progressive centronuclear myopathy. PLoS Genet 9:e1003430, 2013

127. Bohm J, Biancalana V, Malfatti E, et al: Adult-onset autosomal dominant centronuclear myopathy due to BIN1 mutations. Brain 137:3160-3170, 2014

128. Garibaldi M, Bohm J, Fattori F, et al: Novel dominant mutation in BIN1 gene causing mild centronuclear myopathy revealed by myalgias and CK elevation. J Neuromuscul Dis 3:111-114, 2016

129. Agrawal PB, Pierson CR, Joshi M, et al: SPEG interacts with myotubularin, and its deficiency causes centronuclear myopathy with dilated cardiomyopathy. Am J Hum Genet 95:218-226, 2014
130. Wang H, Castiglioni C, Kacar Bayram A, et al: Insights from genotypephenotype correlations by novel SPEG mutations causing centronuclear myopathy. Neuromuscul Disord 27:836-842, 2017

131. Majczenko K, Davidson AE, Camelo-Piragua S, et al: Dominant mutation of CCDC78 in a unique congenital myopathy with prominent internal nuclei and atypical cores. Am J Hum Genet 91:365-371, 2012

132. Pajusalu S, Talvik I, Noormets K, et al: De novo exonic mutation in MYH7 gene leading to exon skipping in a patient with early onset muscular weakness and fiber-type disproportion. Neuromuscul Disord 26:236-239, 2016

133. Fiorillo C, Astrea G, Savarese M, et al: Italian network on congenital myopathies: MYH7-related myopathies: Clinical, histopathological and imaging findings in a cohort of Italian patients. Orphanet J Rare Dis 11, 2016. 91-016-0476-1

134. Willis T, Hedberg-Oldfors C, Alhaswani Z, et al: A novel MYH2 mutation in family members presenting with congenital myopathy, ophthalmoplegia and facial weakness. J Neurol 263:1427-1433, 2016

135. Tsabari R, Daum H, Kerem E, et al: Congenital myopathy due to myosin heavy chain 2 mutation presenting as chronic aspiration pneumonia in infancy. Neuromuscul Disord 27:947-950, 2017

136. Pokrzywa M, Norum M, Lengqvist J, et al: Developmental MYH3 myopathy associated with expression of mutant protein and reduced expression levels of embryonic MyHC. PLoS One 10:e0142094, 2015

137. Chong JX, Burrage LC, Beck AE, et al: Autosomal-dominant multiple pterygium syndrome is caused by mutations in MYH3. Am J Hum Genet 96:841-849, 2015

138. Schartner V, Romero NB, Donkervoort S, et al: Dihydropyridine receptor (DHPR, CACNA1S) congenital myopathy. Acta Neuropathol $133: 517-533,2017$

139. Zaharieva IT, Thor MG, Oates EC, et al: Loss-of-function mutations in SCN4A cause severe foetal hypokinesia or 'classical' congenital myopathy. Brain 139:674-691, 2016

140. Gonorazky HD, Marshall CR, Al-Murshed M, et al: Congenital myopathy with "corona" fibres, selective muscle atrophy, and craniosynostosis associated with novel recessive mutations in SCN4A. Neuromuscul Disord 27:574-580, 2017

141. Mercier S, Lornage X, Malfatti E, et al: Expanding the spectrum of congenital myopathy linked to recessive mutations in SCN4A. Neurology 88:414-416, 2017

142. Vasli N, Harris E, Karamchandani J, et al: Recessive mutations in the kinase ZAK cause a congenital myopathy with fibre type disproportion. Brain 140:37-48, 2017

143. Spielmann M, Kakar N, Tayebi N, et al: Exome sequencing and CRISPR/Cas genome editing identify mutations of ZAK as a cause of limb defects in humans and mice. Genome Res 26:183-191, 2016 